\title{
Biosynthesis of Alkali-insoluble Cell-wall Glucan in Schizophyllum commune Protoplasts
}

\author{
By A. S. M. SONNENBERG, J. H. SIETSMA* AND J. G. H. WESSELS \\ Department of Developmental Plant Biology, Biological Centre, University of Groningen, Haren, \\ The Netherlands
}

(Received 23 March 1982)

\begin{abstract}
Biosynthesis of cell-wall glucans was studied during regeneration of protoplasts from Schizophyllum commune. Double-labelling experiments using $\left[{ }^{14} \mathrm{C}\right] \mathrm{glucose}$ and $\left[{ }^{3} \mathrm{H}\right] \mathrm{glucose}$ indicated a larger pool size of precursors for an alkali-insoluble $(1 \rightarrow 3)$ - $\beta$-glucan than for the other cell-wall components, $(1 \rightarrow 3)-\alpha$-glucan and chitin. Pulse-chase experiments established the existence of a water-soluble, partly alkali-soluble $(1 \rightarrow 3)$ - $\beta$-glucan as a precursor for the alkali-insoluble wall glucan, containing only $(1 \rightarrow 3)-\beta$-linkages. Polyoxin $D$, an inhibitor of chitin synthase, completely arrested accumulation of alkali-insoluble $(1 \rightarrow 3)$ - $\beta$-glucan. This antibiotic did not inhibit the synthesis of the water-soluble glucan, but prevented the incorporation of this material into the alkali-insoluble glucan/chitin complex. Cycloheximide added at the start of regeneration prevented the synthesis of the alkali-insoluble $(1 \rightarrow 3)$ - $\beta$-glucan and of the water-soluble glucan precursor, whereas no effect on the formation of the alkali-insoluble glucan was observed when cycloheximide was added $3 \mathrm{~h}$ after the onset of the regeneration.
\end{abstract}

\section{INTRODUCTION}

The hyphal wall of the basidiomycete Schizophyllum commune grown in culture for $5 \mathrm{~d}$ contains a water-soluble $(1 \rightarrow 3)-\beta /(1 \rightarrow 6)$ - $\beta$-glucan (mucilage), an alkali-soluble $(1 \rightarrow 3)$ - $\alpha$-D-glucan (S-glucan) and an alkali-insoluble complex of $(1 \rightarrow 3)-\beta /(1 \rightarrow 6)-\beta$-D-glucan (R-glucan) with chitin (Wessels et al., 1972; Sietsma \& Wessels, 1977). The insolubility of the glucan in the alkaliinsoluble complex has been explained by the presence of covalent linkages between this glucan and chitin (Sietsma \& Wessels, 1979).

In the present study regeneration of protoplasts was used as a system to study biosynthesis of these wall components. It has been shown previously that protoplasts of $S$. commune are fully capable of regenerating a new wall and reverting to normal hyphal growth (de Vries \& Wessels, 1975; van der Valk \& Wessels, 1976). These earlier studies showed (i) the synthesis of S-glucan and chitin started after a very short lag period, but synthesis of alkali-insoluble glucan was delayed for several hours; (ii) polyoxin $\mathrm{D}$, an antibiotic inhibiting chitin synthase, prevented synthesis of both chitin and R-glucan and also the reversion to hyphal growth; and (iii) cycloheximide prevented both the formation of R-glucan and the reversion to hyphal growth, while the formation of chitin and S-glucan was seemingly unimpaired for several hours. The present results give evidence for a water-soluble $(1 \rightarrow 3)$ - $\beta$-D-glucan functioning as precursor for the alkali-insoluble $(1 \rightarrow 3)-\beta$-D-glucan in a glucan/chitin complex and emphasize the importance of secondary polysaccharide modifications in wall construction.

\section{METHODS}

Grouth of mycelium and preparation of protoplasts. Dikaryotic fruiting mycelium of Schizophyllum commune, obtained by mating strains 1-40 (CBS 344.81) and 1-50 (CBS 342.81), was grown at $24{ }^{\circ} \mathrm{C}$ on minimal medium (Dons et al., 1979) supplemented with $15 \mathrm{~g} \mathrm{agar}^{-1}$ in Petri dishes placed upside down. Basidiospores accumulating on the lids were collected regularly and stored at $-40^{\circ} \mathrm{C}$ in sterile water. Mycelium was grown from 
basidiospores inoculated at a concentration of $1.2 \times 10^{7} \mathrm{ml}^{-1}$ in liquid minimal medium and incubated for $24 \mathrm{~h}$ at $24^{\circ} \mathrm{C}$ on a rotary shaker at 250 r.p.m. The mycelium was harvested by centrifugation $(2000 \mathrm{~g}, 20 \mathrm{~min})$ and washed once with $0.5 \mathrm{M}-\mathrm{MgSO}_{4}$.

Protoplasts were prepared by incubating mycelium $\left(100 \mathrm{mg}\right.$ wet $\left.\mathrm{wt} \mathrm{ml}^{-1}\right)$ in a medium containing $0.5 \mathrm{M}-\mathrm{MgSO}_{+}$ and Trichoderma wall lytic enzyme preparation $\left(0.5 \mathrm{mg}\right.$ protein $\left.\mathrm{ml}^{-1}\right)$ for $16 \mathrm{~h}$ at $24^{\circ} \mathrm{C}$ on a rotary shaker at 50 r.p.m. (de Vries \& Wessels, 1972). Occasionally instead of the Trichoderma wall lytic enzyme preparation, Novo cell wall lytic enzyme SP234 (generously donated by Novo Industri, Bagsvaerd, Denmark) was used with essentially the same results. Protoplasts were isolated and washed by flotation as described earlier (de Vries \& Wessels, 1972).

Regeneration of protoplasts and isolation of polysaccharide fractions. Protoplasts $\left(10^{7}-10^{8} \mathrm{ml}^{-1}\right)$ were suspended in regeneration medium consisting of minimal medium containing $10 \mathrm{mg}$ glucose $\mathrm{ml}^{-1}$ supplemented with $0.5 \mathrm{M}-$ $\mathrm{MgSO}_{\perp}$ and incubated under aerobic conditions (in a shallow layer) at $25^{\circ} \mathrm{C}$. Samples were taken at intervals and the regeneration process stopped by adding $2 \mathrm{vol}$. methanol. The precipitate was collected by centrifugation, washed with $66 \%$ methanol, and protein was extracted by digestion with pronase (Calbiochem, $1 \mathrm{mg} \mathrm{ml}^{-1}$ in $0.01 \mathrm{M}$-phosphate buffer, $\mathrm{pH} 7.5$, for $18 \mathrm{~h}$ ). Subsequently the digest was heated at $100^{\circ} \mathrm{C}$ for $1 \mathrm{~h}$, the insoluble residue was removed by centrifugation and water-soluble polysaccharides were precipitated from the supernatant by adding 2 vol. methanol. Alternatively, the pronase treatment was omitted and the samples were extracted with a mixture of 1 vol. $1 \mathrm{M}-\mathrm{KOH}$ and 2 vol. ethanol for $10 \mathrm{~min}$ at $60{ }^{\circ} \mathrm{C}$, washed with $66 \%(\mathrm{v} / \mathrm{v})$ ethanol until neutral, dried, and then extracted with water at $100{ }^{\circ} \mathrm{C}$ for $1 \mathrm{~h}$. The water-insoluble residue was extracted with $1 \mathrm{M}-\mathrm{KOH}$ at $60^{\circ} \mathrm{C}$ for 20 min under $\mathrm{N}_{2}$ and $(1 \rightarrow 3)$ - $\alpha$-glucan was precipitated by acidification of the alkaline extract with acetic acid, recovered by centrifugation and dissolved in $0.5 \mathrm{M}-\mathrm{KOH}$ (Wessels et al., 1972). The other alkali-soluble polysaccharides were precipitated by adding 2 vol. ethanol to the supernatant and dissolved in water after centrifugation. This glucan contained predominantly $(1 \rightarrow 3)$ - $\beta$-glucan (see Results) and will therefore be called the alkali-soluble $\beta$-glucan fraction. The alkali-insoluble $\beta$-glucan was solubilized by treating the alkali-insoluble residue with $0.55 \mathrm{M}-\mathrm{HCl}$ at $100^{\circ} \mathrm{C}$ for $1 \mathrm{~h}$ and subsequently with $1 \mathrm{M}-\mathrm{KOH}$ at $60^{\circ} \mathrm{C}$ for $20 \mathrm{~min}$ and combining the extracts (Sietsma \& Wessels, 1977). The chitin in the insoluble residue was hydrolysed with $6 \mathrm{M}-\mathrm{HCl}$ at $120^{\circ} \mathrm{C}$ for $2 \mathrm{~h}$ under $\mathrm{N}_{2}$ in closed tubes, the hydrolysate was dried in a desiccator over $\mathrm{KOH}$ and $\mathrm{P}_{2} \mathrm{O}_{5}$ and dissolved in water.

Chemical assay's. Glucan in the fractions was estimated with the anthrone reagent (Fairbairn, 1953) and chitin was determined by analysing glucosamine in the hydrolysed fraction by the procedure of Johnson (1971).

Radioactice labelling of fractions. In double-labelling experiments protoplasts were regenerated in the presence of $5 \mu \mathrm{Ci}\left[6^{-1+} \mathrm{C}\right]$ glucose $\mathrm{ml}^{-1}\left[\mathrm{sp}\right.$. act. $\left.10 \mathrm{mCi} \mathrm{mmol}^{-1}(1 \mathrm{mCi}=37 \mathrm{MBq})\right]$ and after $3 \mathrm{~h}, 25 \mu \mathrm{Ci}\left[6-{ }^{3} \mathrm{H}\right] \mathrm{glucose} \mathrm{ml}^{-1}$ (sp. act. $25 \mathrm{Ci} \mathrm{mmol}^{-1}$ ) was added. Incorporation was stopped by adding 1 vol. $10 \%(\mathrm{w} / \mathrm{v})$ trichloroacetic acid and the sediment collected by centrifugation. Protein was extracted from the pellet by digestion with pronase and the residue was fractionated as described above except that chitin was dissolved by digestion with the Trichoderma enzyme complex. Samples of the different fractions were oxidized (Tri-Carb sample oxidizer, Packard) and ${ }^{3} \mathrm{H}$ and ${ }^{1+} \mathrm{C}$ counted separately according to the instructions of the manufacturer.

In pulse-chase experiments a pulse of $10 \mu \mathrm{Ci}\left[\mathrm{U}-{ }^{1+} \mathrm{C}\right] \mathrm{glucose} \mathrm{ml}^{-1}$ (sp. act. $250 \mathrm{mCi} \mathrm{mmol}^{-1}$ ) was given for $3 \mathrm{~h}$, then the radioactivity was chased by adding 9 vol. unlabelled regeneration medium. In a parallel experiment the dilution was done with medium containing the same amount of radioactivity as during the pulse, in order to correct for the incorporation of residual radioactivity during the chase.

The R-glucan/chitin complex labelled with ${ }^{1+} \mathrm{C}$ was isolated from $5 \mathrm{~d}$ old mycelium cultivated in minimal medium supplemented with $\left.0 \cdot 1 \mathrm{mCi}\left[\mathrm{U}^{-1+} \mathrm{C}\right] \mathrm{g}\right] \mathrm{ucose}\left(\mathrm{sp}\right.$. act. $340 \mathrm{mCi} \mathrm{mmol}^{-1}$ ) per $100 \mathrm{ml}$ medium. The radioactivity in the various fractions was estimated by mixing $0.1 \mathrm{ml}$ with $2 \mathrm{ml}$ of Hydroluma (Baker Chemicals) and counting in a liquid scintillation counter.

Characterization of glucan fractions. Glucan fractions were digested with: exo-( $1 \rightarrow 3)$ - $\beta$-glucanase (EC 3.2.1.58) $\left(1.5\right.$ units $\left.\mathrm{ml}^{-1}\right)$ isolated from Sporotrichum dimorphosum and purified according to Sietsma \& Wessels (1977), pancreatic $\alpha$-amylase (EC 3.2.1 .1, Sigma) (1.9 units $\mathrm{ml}^{-1}$ ), or $\beta$-amylase (EC 3.2.1 .2, Merck) (4.5 units $\mathrm{ml}^{-1}$ ) in $5 \mathrm{~mm}$-sodium acetate buffer $\mathrm{pH} 5.8$ at $30^{\circ} \mathrm{C}$ for $16 \mathrm{~h}$, with a few drops of toluene added to prevent bacterial growth. Products were separated by thin-layer chromatography in pyridine/ethyl acetate/acetic acid/ water $(5: 5: 1: 3$, by vol.) and radioactivity on the thin-layer plates was monitored with a Berthold scanner. Dimethyl sulphoxide (DMSO) treatment $\left(2 \mathrm{~h}, 120^{\circ} \mathrm{C}\right.$, under $\left.\mathrm{N}_{2}\right)$ and selective depolymerization of chitin by nitrous acid after deacetylation by $40 \%(\mathrm{w} / \mathrm{v}) \mathrm{NaOH}$ have been described before (Sietsma \& Wessels, 1979, 1981).

\section{RESULTS}

Pool size of precursor material for the different cell-wall fractions

Previously de Vries \& Wessels (1975) showed that in regenerating protoplasts the synthesis of the alkali-insoluble wall fraction had a lag period of about $3 \mathrm{~h}$. To investigate the possibility that 
Table 1. Estimation of the pool size of precursor material for different mycelial fractions

Protoplasts were regenerated in the presence of $5 \mu \mathrm{Ci}\left[6^{-1+} \mathrm{C}\right]$ glucose $\mathrm{ml}^{-1}$. After $3 \mathrm{~h}$ of regeneration 25 $\mu \mathrm{Ci}\left[6-{ }^{3} \mathrm{H}\right]$ glucose $\mathrm{ml}^{-1}$ was added. At the times indicated $1 \mathrm{ml}$ samples were taken, regeneration was stopped by adding $1 \mathrm{ml} 10^{\circ}$ trichloroacetic acid and the sediment was collected by centrifugation. The different fractions were then obtained from the pellet by the procedures indicated in Methods.

$\mathrm{H} /{ }^{+} \mathrm{C}$ ratio in mycelial fractions:

Time after addition of $\left[{ }^{3} \mathrm{H}\right]$ glucose $(\mathrm{h})$

$\begin{array}{cccc}\text { Protein } & (1 \rightarrow 3)-\alpha \text {-Glucan } & \begin{array}{c}\text { Alkali-insoluble } \\ (1 \rightarrow 3) \text { - } \beta \text {-glucan }\end{array} & \text { Chitin } \\ 2.70 & 2.78 & 1.89 & 3.13 \\ 3.13 & 3.13 & 2.33 & 3.45 \\ 3.85 & 3.85 & 2.56 & 3.70\end{array}$
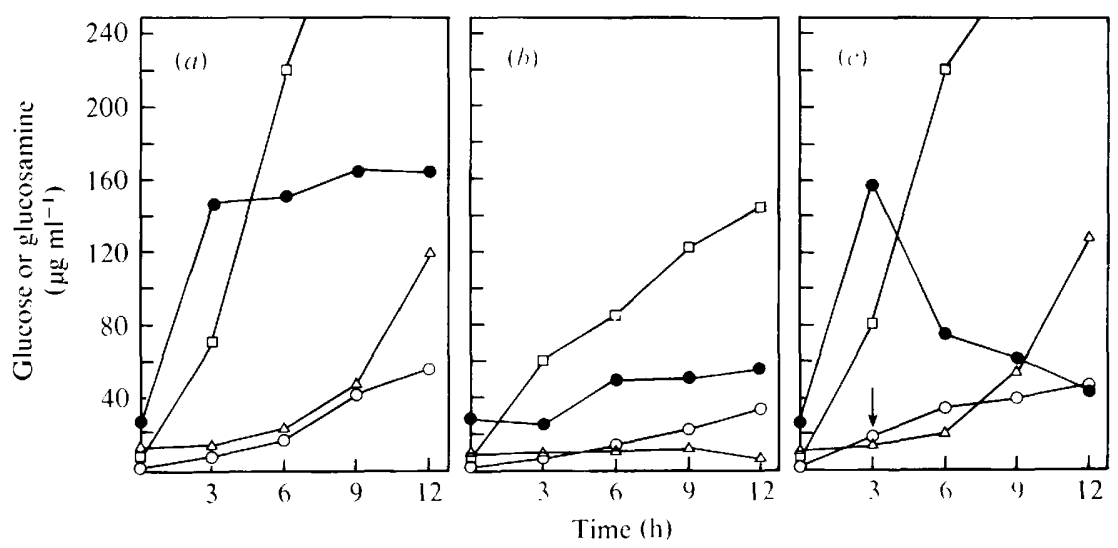

Fig. 1. Accumulation of glucans (measured as anthrone-positive material) and chitin (measured as glucosamine) during regeneration of protoplasts of Schizophyllum commune. Water-soluble glucan: $\square$, ( $\rightarrow 3$ )- $x$-glucan: $\triangle$, alkali-insoluble glucan; $\bigcirc$, chitin. (a) Control; $(b) 0.5 \mu$ g cycloheximide $\mathrm{ml}^{-1}$ added at the start of regeneration: (c) $0.5 \mu \mathrm{g}$ cycloheximide $\mathrm{ml}^{-1}$ added $3 \mathrm{~h}$ after the start of regeneration.

during this period precursor material was accumulated which was subsequently transferred to the alkali-insoluble wall fraction, protoplasts were regenerated in the presence of $\left[{ }^{14} \mathrm{C}\right]$ glucose for the first $3 \mathrm{~h}$ then $\left[{ }^{3} \mathrm{H}\right]$ glucose was added in excess and the change in the ${ }^{3} \mathrm{H} /{ }^{14} \mathrm{C}$ ratio was estimated in various cell fractions during the ensuing regeneration process. This ratio increased in the alkali-insoluble glucan fraction at a lower rate than in the other fractions (Table 1), indicating that the alkali-insoluble glucan of the cell wall was synthesized from a larger pool of previously synthesized materials than the other cell-wall fractions. The change of the ${ }^{3} \mathrm{H} /{ }^{14} \mathrm{C}$ ratio in the other fractions was almost the same, indicating a pool of precursors of roughly equal size.

\section{The effect of cycloheximide}

When regeneration was followed by estimating the accumulation of glucan (anthrone value) in the different cell fractions, it appeared that a water-soluble glucan was initially synthesized at a very high rate (Fig. 1a). In agreement with earlier results (de Vries \& Wessels, 1975) the synthesis of alkali-insoluble glucan was very slow during this period, while $(1 \rightarrow 3)$ - $\alpha$-glucan and chitin synthesis proceeded at a steady rate from the start of regeneration (Fig. 1 $a$ ). When cycloheximide was added at the start of the regeneration at a concentration that inhibits protein synthesis completely (de Vries \& Wessels, 1975), the accumulation of both the alkali-insoluble glucan and the water-soluble glucan were inhibited. On the other hand, $(1 \rightarrow 3)$ - $\alpha$-glucan and chitin accumulation were less affected, and only after 3 to $6 \mathrm{~h}$ did accumulation of these 


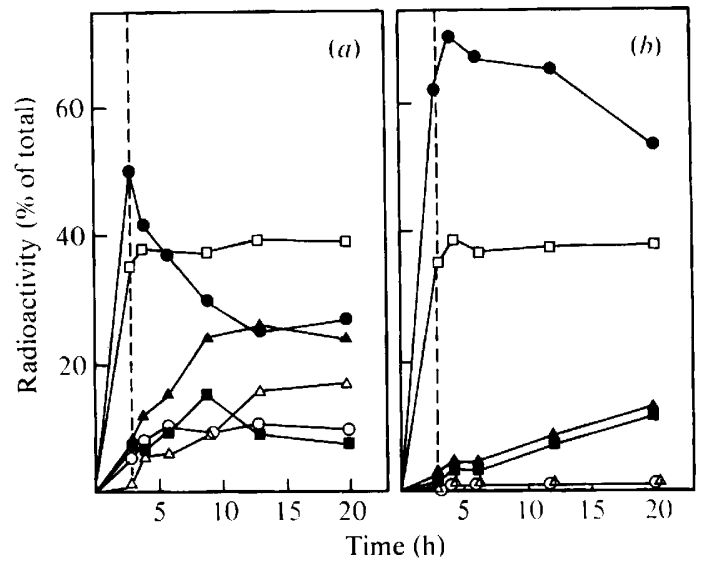

Fig. 2. Distribution of radioactivity in a pulse-chase experiment among the various glycans during regeneration of protoplasts of $S$. commune in the absence $(a)$ and presence $(b)$ of polyoxin D $(5 \mu \mathrm{g}$ $\left.\mathrm{ml}^{-1}\right)$. Protoplasts $\left(10^{8} \mathrm{ml}^{-1}\right)$ were regenerated in the presence of $10 \mu \mathrm{Ci}$ [U-14 C]glucose $\mathrm{ml}^{-1}$. After $3 \mathrm{~h}$ the radioactivity was diluted by adding 9 vol. unlabelled regeneration medium. At the times indicated samples were taken and glycan fractions isolated. The uptake of residual radioactivity was corrected for in a control experiment where $9 \mathrm{vol}$. radioactive regeneration medium $\left(10 \mu \mathrm{Ci}\left[\mathrm{U}-{ }^{14} \mathrm{C}\right]\right.$ glucose $\left.\mathrm{ml}^{-1}\right)$ was added. $\bigcirc$, Water-soluble glucan; $\square,(1 \rightarrow 3)$ - $\alpha$-glucan; $\triangle$, alkali-insoluble $\beta$-glucan; $O$, chitin; $\mathbf{\square}$, alkali-soluble $\beta$-glucan; $\boldsymbol{\Delta}$, the sum of alkali-soluble and alkali-insoluble $\beta$-glucan.

compounds decrease (Fig. $1 \mathrm{~b}$ ). However, when cycloheximide was added $3 \mathrm{~h}$ after the onset of regeneration, thus allowing the synthesis of water-soluble glucan, the accumulation of alkaliinsoluble glucan was not affected during the time course of the experiment; in this case the water-soluble glucan fraction decreased sharply immediately after addition of cycloheximide (Fig. 1c). This indicates that the inhibition of the accumulation of the alkali-insoluble glucan by cycloheximide as shown in Fig. $1(b)$ was mainly through inhibition of the synthesis of the watersoluble glucan. The antibiotic did not seem to interfere with the flow of material from this fraction into the alkali-insoluble glucan.

\section{Pulse-chase experiments with radioactive glucose}

During regeneration, protoplasts were first labelled with $\left[{ }^{14} \mathrm{C}\right]$ glucose, after which the label was diluted 10 times. Figure $2(a)$ shows that during the chase radioactivity was transferred quantitatively from the water-soluble fraction into the alkali-soluble and the alkali-insoluble glucan fractions, whereas the alkali-soluble $(1 \rightarrow 3)$ - $\alpha$-glucan and chitin fractions appeared stable. In fact the kinetics suggest that there is a transfer of glucan from the water-soluble fraction through the alkali-soluble fraction into the alkali-insoluble fraction. When polyoxin $\mathrm{D}$, an inhibitor of the chitin synthase, was added at the start of regeneration, no chitin and hardly any alkali-insoluble glucan was formed and during the chase only a small part of the radioactivity was transferred from the water-soluble into the alkali-soluble $\beta$-glucan fraction (Fig. $2 b$ ). This suggests that the flow of glucans from the water-soluble fraction into the alkali-insoluble glucan fraction can only occur when chitin is synthesized, whereas the flow into the alkalisoluble $\beta$-glucan fraction was inhibited.

\section{Characterization of the precursors for alkali-insoluble glucan}

When protoplasts were regenerated in the presence of $\left[{ }^{14} \mathrm{C}\right]$ glucose for $5 \mathrm{~h}, 95 \%$ of the radioactive water-soluble glucan sedimented at $1200 \mathrm{~g}$ after the addition of an equal volume of $0.5 \mathrm{M}$-mannitol to decrease the density of the protoplasts. This means that this glucan was not excreted into the medium, but remained closely associated with the cells. When the watersoluble material was incubated with exo- $(1 \rightarrow 3)$ - $\beta$-glucanase [free from amylase, $(1 \rightarrow 6)$ - $\beta$ glucanase and chitinase] most of it was degraded and yielded only glucose (Fig. $5 a$ ), indicating the presence of $(1 \rightarrow 3)$ - $\beta$-glucan without $(1 \rightarrow 6)$-linkages. The remaining part was degraded by $\alpha$ and $\beta$-amylase and probably consisted of glycogen. 


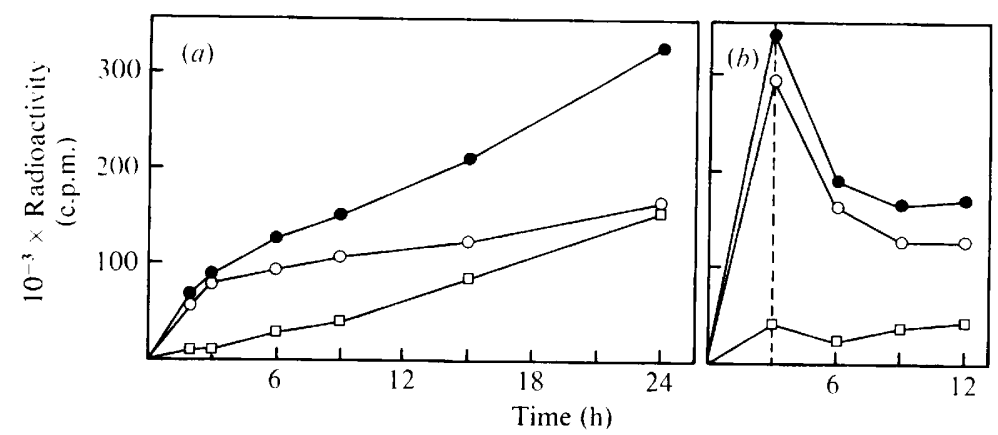

Fig. 3. Amount of water-soluble glucan degradable by exo-( $\rightarrow 3)$ - $\beta$-glucanase. Water-soluble fractions isolated from protoplasts regenerating under either continuous labelling with $10 \mu \mathrm{Ci}$ [ $\mathrm{U}-{ }^{14} \mathrm{C}$ ]glucose

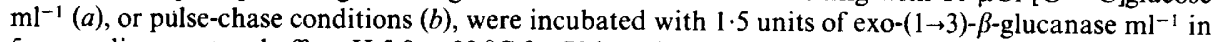
$5 \mathrm{mM}$-sodium acetate buffer pH 5.8 at $30^{\circ} \mathrm{C}$ for $72 \mathrm{~h}$ under toluene. The whole sample was counted and subjected to thin-layer chromatography and the percentage of glucose liberated was determined. Total water soluble glucan; $\bigcirc$, material digested by exo-( $1 \rightarrow 3)$ - $\beta$-glucanase; $\square$, material undigested by exo-(1 $\rightarrow 3)-\beta$-glucanase.

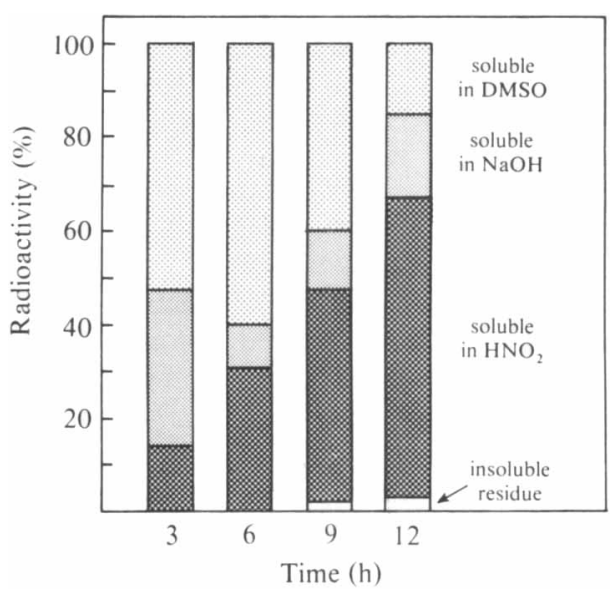

Fig. 4. Solubility characteristics of the newly-formed $\beta$-glucan/chitin complex. Protoplasts were regenerated in the presence of $10 \mu \mathrm{Ci}\left[\mathrm{U}^{-14} \mathrm{C}\right] \mathrm{glucose} \mathrm{ml}^{-1}$. At the times indicated samples were withdrawn, the alkali-insoluble residue ( $\beta$-glucan/chitin complex) isolated and extracted in succession with DMSO $\left(2 \mathrm{~h}, 120^{\circ} \mathrm{C}\right), 40 \%(\mathrm{w} / \mathrm{v}) \mathrm{NaOH}\left(1 \mathrm{~h}, 100^{\circ} \mathrm{C}\right)$ and nitrous acid $\left(2 \mathrm{M}-\mathrm{NaNO}_{2}+2 \mathrm{M}-\mathrm{HCl}, 1 \cdot 5 \mathrm{~h}\right.$ at room temperature). After each extraction procedure the radioactivity was measured in the residue and the percentage of solubilized material calculated.

When protoplasts were regenerated in the continuous presence of $\left[{ }^{14} \mathrm{C}\right]$ glucose, the $(1 \rightarrow 3)-\beta$ glucanase-sensitive material accumulated very rapidly during the first $3 \mathrm{~h}$ of regeneration, after which the amount of this material remained fairly constant. On the other hand, the presumed glycogen in the water-soluble fraction accumulated at a steady rate (Fig. $3 a$ ). This would indicate that after a certain pool size of water-soluble $(1 \rightarrow 3)-\beta$-glucan is built up, this pool becomes subject to turnover. Indeed, pulse-chase experiments showed that only exo-( $1 \rightarrow 3)-\beta$ glucanase-sensitive material disappeared from the water-soluble fraction (Fig. $3 b$ ), the amount of radioactivity in the $\beta$-glucanase-resistant part remained fairly stable, indicating no turnover of this material. Moreover, the precursor material soluble in alkali and not belonging to the S-glucan fraction was degraded by exo-( $1 \rightarrow 3)-\beta$-glucanase by more than $90 \%$ and gave only glucose as product.

\section{Characterization of the alkali-insoluble complex}

Previously it was shown that $(1 \rightarrow 3)-\beta /(1 \rightarrow 6)-\beta$-glucan and chitin in the hyphal wall are covalently linked into an alkali-insoluble complex. The glucan could not be extracted with 


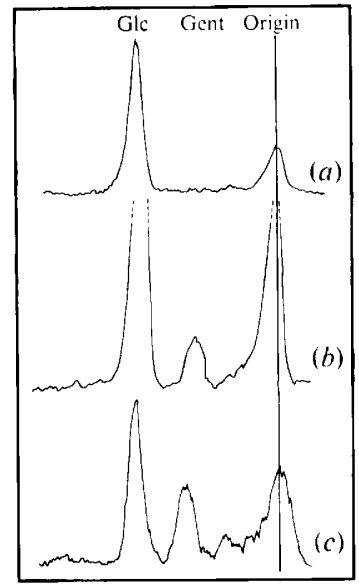

Fig. 5. Radiochromatographic tracings of thin-layer chromatograms of the solubilized products after treatments with exo- $(1 \rightarrow 3)-\beta$-glucanase $\left(1.5\right.$ units $\mathrm{ml}^{-1}$ in sodium acetate buffer $\mathrm{pH} 5.8$ at $30^{\circ} \mathrm{C}$ for $48 \mathrm{~h}$ under toluene) of the following ${ }^{14} \mathrm{C}$-labelled substrates: $(a)$ water-soluble fraction isolated from regenerating protoplasts $(24 \mathrm{~h}) ;(b) \beta$-glucan/chitin complex isolated from regenerating protoplasts $(24 \mathrm{~h}) ;(c)$ $\beta$-glucan/chitin complex isolated from $5 \mathrm{~d}$ old hyphae. The components were identified by co-chromatography with standards. Glc, glucose; Gent, gentiobiose.

DMSO or with $40 \% \mathrm{NaOH}$ at $100{ }^{\circ} \mathrm{C}$, but only after depolymerization of chitin (Sietsma \& Wessels, 1979, 1981). In order to investigate whether the newly formed alkali-insoluble glucan on protoplasts behaved similarly, the alkali-insoluble fraction of regenerating protoplasts was successively extracted with DMSO, $40 \% \mathrm{NaOH}$ and nitrous acid. Figure 4 shows that a large part of the alkali-insoluble glucan of these regenerated protoplasts can be removed by DMSO and $\mathrm{NaOH}$ but that these fractions decreased as regeneration progressed. However, after $12 \mathrm{~h}$, at which time hyphae were present, only $60 \%$ of the alkali-insoluble wall had solubility characteristics typical for the alkali-insoluble wall glucan of $5 \mathrm{~d}$ old mycelium (Sietsma \& Wessels, 1979, 1981).

The alkali-insoluble glucan from regenerating protoplasts could be degraded by $80 \%$ by exo$(1 \rightarrow 3)-\beta$-glucanase. During the early stages of regeneration the only degradation product was glucose (Fig. $5 a$ ) whereas after $12 \mathrm{~h}$ regeneration a small amount of gentiobiose was detected (Fig. $5 b$ ). This contrasts with the alkali-insoluble wall glucan (R-glucan) from $5 \mathrm{~d}$ old mycelium, in which the major breakdown products of exo- $(1 \rightarrow 3)-\beta$-glucanase action are gentiobiose and $(1 \rightarrow 6)$ - $\beta$-linked oligosaccharides (Fig. $5 c$; Sietsma \& Wessels, 1977).

\section{DISCUSSION}

In almost all fungal walls, except those of the Zygomycetes, an alkali-insoluble glucan is present closely associated with chitin. In previous studies on $5 \mathrm{~d}$ old hyphal walls of $S$. commune it was shown that this glucan is highly branched and contains $(1 \rightarrow 3)-\beta$ and $(1 \rightarrow 6)-\beta$ linkages (Sietsma \& Wessels, 1977), and that the insolubility of this glucan could be explained by its covalent linkage to chitin (Sietsma \& Wessels, 1979). On the other hand, in other fungal species part of the alkali-insoluble glucan can be extracted by DMSO or $40 \% \mathrm{NaOH}$. The solubilization of the remaining glucan after depolymerization of chitin was used in these studies as a criterion for linkage of this glucan to chitin (Sietsma \& Wessels, 1981).

The present study shows that the alkali-insoluble $\beta$-glucan initially formed on regenerated protoplasts, unlike the alkali-insoluble wall $\beta$-glucan of $5 \mathrm{~d}$ old mycelium, contains few $(1 \rightarrow 6)$ linkages and appears to be a homopolymer of $(1 \rightarrow 3)$ - $\beta$-glucan. In addition, only a part of this glucan remains insoluble after treatment with hot DMSO or $40 \% \mathrm{NaOH}$, this part increasing with regeneration time. This raises the question whether only the latter fraction may be linked to 
chitin, since it becomes soluble after depolymerization of the deacetylated chitin. Synthesis of the whole alkali-insoluble $\beta$-glucan fraction is inhibited by addition of polyoxin $D$, suggesting also that the fractions removed by hot DMSO or $\mathrm{NaOH}$ can only be produced with concomitant chitin synthesis. Therefore, the possibility has to be considered that this part of the alkaliinsoluble $\beta$-glucan is also characterized by linkages between glucan and chitin chains in which the latter have not yet interacted to form a highly insoluble complex as in crystalline chitin.

Several lines of evidence suggest that the alkali-insoluble $(1 \rightarrow 3)$ - $\beta$-glucan on regenerated protoplasts is derived from a hot-water soluble $(1 \rightarrow 3)$ - $\beta$-glucan. This water-soluble glucan is initially synthesized at a high rate and then is converted into the alkali-insoluble $(1 \rightarrow 3)-\beta$-glucan fraction, probably via an intermediate step in which the glucan is no longer soluble in hot water but remains soluble in $1 \mathrm{M}-\mathrm{KOH}$. This turnover is prevented by polyoxin $\mathrm{D}$, suggesting that simultaneous synthesis of chitin and linkage to glucan plays a role in the process of insolubilization. This process is not inhibited by cycloheximide which does, however, inhibit the synthesis of the water-soluble precursor $(1 \rightarrow 3)$ - $\beta$-glucan with the result that the pool of this glucan is quickly emptied. The effect is fairly specific with regard to wall synthesis because neither chitin nor $(1 \rightarrow 3)$ - $\alpha$-glucan synthesis are appreciably affected. Apparently the synthases for these wall components are fairly stable, whereas the synthase for the water-soluble $(1 \rightarrow 3)$ - $\beta$-glucan is not. However, the rapid cessation of synthesis of this glucan after addition of cycloheximide suggests that other factors may be involved. Cycloheximide is known to influence processes other than protein synthesis. In Aspergillus nidulans (Sternlicht et al., 1973) and S. commune (J. H. Sietsma \& J. G. H. Wessels, unpublished observations) it prevents hyphal growth but also displaces the synthesis of chitin and other wall components from the apex towards more subapical regions. In contrast to the present findings, cycloheximide prevents the incorporation of $N$-acetylglucosamine but not of glucose into the alkali-insoluble wall fraction of regenerating Saccharomyces cerevisiae protoplasts (Farkas \& Svoboda, 1980).

A homopolymer of $(1 \rightarrow 3)-\beta$-glucan is also formed on Saccharomyces cerevisiae protoplasts (Kreger \& Kopecka, 1976) without the additional $(1 \rightarrow 6)$ - $\beta$-linked residues that are present in the normal walls of this yeast (Manners et al., 1973a, b; Fleet \& Manners, 1976). Similarly, experiments with isolated enzyme preparations from different fungi have yielded homopolymers of $(1 \rightarrow 3)-\beta$-glucans, whereas the alkali-insoluble $\beta$-glucans from the walls of the fungi contained a branched $(1 \rightarrow 3)-\beta /(1 \rightarrow 6)-\beta$-glucan (Wang \& Bartnicki Garcia, 1976; Shematek et al., 1980; Larriba et al., 1981). However, when enzyme preparations contaminated with wall residues were used, the newly-synthesized $\beta$-glucan contained both $(1 \rightarrow 3)$ and $(1 \rightarrow 6)$ linkages (Lopez-Romero \& Ruiz-Herrera, 1977). Apparently, the enzymes catalysing the synthesis of the two types of linkage are easily dissociated in these artificial systems.

Nothing is known about the site of formation of the hot water-soluble $(1 \rightarrow 3)$ - $\beta$-glucan. This could be within the cytoplasm or at the outside of the plasma membrane. If synthesis occurs within the cytoplasm, the polymer is presumably excreted to the outside of the plasma membrane, where it becomes associated with chitin chains. There is evidence for chitin synthesis occurring at the outside of the plasma membrane (van der Valk \& Wessels, 1977). Experiments to detect the site of synthesis and translocation of the $\beta$-glucan precursor by autoradiography are currently in progress. Regardless of the exact site of synthesis, the present findings suggest that the enzymes which effect coupling of the $\beta$-glucan to chitin chains must operate outside the plasma membrane because one of the sybstrates, chitin, is not formed within the cytoplasm. The lag in formation of the insoluble $\beta$-glucan could thus be explained by assuming that these wallless protoplasts must first synthesize some other wall components, $(1 \rightarrow 3)-\alpha$-glucan and chitin (the latter also serving as a substrate), before external enzymes can be retained by the cell to aid in the coupling process between chitin and glucan. Another possibility would be that during the lag time, and also in the presence of polyoxin $\mathrm{D}$, the translocation of the water-soluble glucan to the outside of the cell is inhibited. Autoradiographic experiments should resolve this point.

It would be of considerable interest if the process of formation of a water-soluble glucan precursor and subsequent incorporation of this glucan into a highly insoluble glucan/chitin complex also occurred during the process of normal wall synthesis at the hyphal apex. Such a mode of wall construction could imply that the wall goes through a gradual series of changes as 
the glucan is insolubilized in the wall. This maturation process could have a bearing on the mechanical properties of the wall, such as plasticity, and would be relevant to mechanisms of apical growth (Green, 1974). Recent experiments in this laboratory show that indeed the $\beta$ glucan component synthesized at the hyphal tip is initially soluble in hot water, but gradually changes into a highly insoluble glucan (J. H. Sietsma \& J. G. H. Wessels, unpublished observations).

\section{REFERENCES}

Dons, J. J. M., VRIES, O. M. H. DE \& WesSELS, J. G. H. (1979). Characterization of the genome of the basidiomycete Schizophyllum commune. Biochimica et biophysica acta 563, 100-112.

FAIRBAIRN, N. J. (1953). A modified anthrone reagent. Chemistry and Industry 72, 86.

FARKAS, V. \& SVOBODA, A. (1980). Kinetics of $\beta$-glucan and chitin formation by cells and protoplasts of the yeast Saccharomyces cerevisiae. Current Microbiology 4, 99-103.

FleEt, G. H. \& MANNERS, D. J. (1976). Isolation and composition of an alkali-soluble glucan from the cell walls of Saccharomyces cerevisiae. Journal of General Microbiology 94, 180-192.

Green, P. B. (1974). Morphogenesis of the cell and organ axis. Biophysical models. Brookhaven Symposia in Biology 25, 166-190.

Johnson, A. R. (1971). An improved method of hexosamine determination. Analytical Biochemistry 44, 628-635.

KREGER, D. R. \& KOPECKA, A. (1976). On the nature and formation of the fibrillar nets produced by protoplasts of Saccharomyces cerevisiae in liquid media. An electronmicroscopic, X-ray diffraction and chemical study. Journal of General Microbiology 92, 207-220.

Larriba, G., Morales, M. \& Ruiz Herrera, J. (1981). Biosynthesis of $\beta$-glucan microfibrils by cellfree extracts from Saccharomyces cerevisiae. Journal of General Microbiology 124, 375-383.

Lopez-Romero, E. \& Ruiz-Herrera, J. (1977). Biosynthesis of $\beta$-glucan by cell-free extracts from Saccharomyces cerevisiae. Biochimica et biophysica acta 500, 372-384.

Manners, D. J., Masson, A. J. \& Patterson, J. C. $(1973 a)$. The structure of a $\beta-(1 \rightarrow 3)$-D-glucan from yeast cell walls. Biochemical Journal 135, 19-30.

Manners, D. J., Masson, A. J. \& Patterson, J. C. $(1973 b)$. The structure of a $\beta-(1 \rightarrow 6)$-D-glucan from yeast cell walls. Biochemical Journal 135, 31-36.

Shematek, E., Braatz, J. A. \& Cabib, E. (1980). Biosynthesis of yeast cell wall. I. Preparation and prop- erties of 1,3- $\beta$-glucan synthetase. Journal of Biological Chemistry 255, 888-894.

Sietsma, J. H. \& Wessels, J. G. H. (1977). Chemical analysis of the hyphal wall of Schizophyllum commune. Biochimica et biophysica acta 496, 225-239.

Sietsma, J. H. \& Wessels, J. G. H. (1979). Evidence for covalent linkages between chitin and $\beta$-glucan in a fungal wall. Journal of General Microbiology 114, 99108.

Sietsma, J. H. \& WesSELS, J. G. H. (1981). Solubility of $(1 \rightarrow 3)-\beta$-D/( $1 \rightarrow 6)-\beta$-D-glucan in fungal walls: importance of presumed linkage between glucan and chitin. Journal of General Microbiology 125, 209-212.

Sternlicht, E., Katz, D. \& Rosenberger, R. F. (1973). Subapical wall synthesis and wall thickening induced by cycloheximide in hyphae of Aspergillus nidulans. Journal of Bacteriology 114, 819-823.

VALK, P. VAN DER \& Wessels, J. G. H. (1976). Ultrastructure and localization of wall polymers during regeneration and reversion of protoplasts of Schizophyllum commune. Protoplasma 90, 65-87.

VAlK, P. van DER \& Wessels, J. G. H. (1977). Light and electron microscopic autoradiography of cell wall regeneration by Schizophyllum commune protoplasts. Acta botanica neerlandica 26, 43-52.

VRIES, O. M. H. DE \& Wessels, J. G. H. (1972). Release of protoplasts from Schizophyllum commune by a lytic enzyme preparation from Trichoderma viride. Journal of General Microbiology 73, 13-22.

VRIES, O. M. H. DE \& Wessels, J. G. H. (1975). Chemical analysis of cell wall regeneration and reversion of protoplasts from Schizophyllum commune. Archives of Microbiology 102, 209-218.

WANG, M. C. \& Bartnicki-Garcia, S. (1976). Synthesis of $(1 \rightarrow 3)$ - $\beta$-glucan microfibrils by a cell free extract from Phytophthora cinnamomi. Archives of Biochemistry and Biophysics 175, 351-354.

Wessels, J. G. H., Kreger, D. R., Marchant, R., RegensburG, B. A. \& DE VRIES, O. M. H. (1972). Chemical and morphological characterization of the hyphal wall surface of the basidiomycete Schizophyllum commune. Biochimica et biophysica acta 273, 346-358. 